\title{
Besifloxacin: a novel anti-infective for the treatment of bacterial conjunctivitis
}

This article was published in the following Dove Press journal:

Clinical Ophthalmology

26 March 2010

Number of times this article has been viewed

Timothy L Comstock'

Paul M Karpecki ${ }^{2}$

Timothy W Morris ${ }^{3}$

Jin-Zhong Zhang ${ }^{4}$

'Global Medical Affairs, Pharmaceuticals, Bausch and Lomb, Inc., Rochester, NY, USA; ${ }^{2}$ Koffler Vision Group, Lexington, KY, USA; ${ }^{3}$ Research and Development Microbiology and Sterilization Sciences, Bausch and Lomb, Inc., Rochester, NY, USA; ${ }^{4}$ Global Preclinical Development, Bausch and Lomb, Inc., Rochester, NY, USA
Correspondence:Timothy L Comstock Global Medical Affairs, Pharmaceuticals, Bausch and Lomb, Inc., I 400 N. Goodman St., Rochester, NY 14609 USA

$\mathrm{Tel}+\mathrm{I}$ (585) 338-663 I

$\mathrm{Fax}+\mathrm{I}(585)$ 338-0273

Email tcomstock@bausch.com
Abstract: Bacterial conjunctivitis, commonly known as pink eye, is demographically unbiased in its prevalence and can be caused by a variety of aerobic and anaerobic bacteria. Timely empiric treatment with a broad-spectrum anti-infective, such as a topical fluoroquinolone, is critical in preventing potentially irreversible ocular damage. However, the rise in ocular methicillin-resistant Staphylococcus aureus isolates and the patterns of fluoroquinolone resistance for patients with other ocular bacterial infections mandate the need for new agents targeted for ocular use. Besifloxacin, a novel broad-spectrum fluoroquinolone, is approved for the treatment of bacterial conjunctivitis. It has a uniquely balanced dual-targeting activity that inhibits both DNA gyrase and topoisomerase IV and is associated with a lower incidence of resistance development. Besifloxacin is not marketed in other formulations, ensuring that its exposure is limited to bacterial populations in and around the eye. This specifically precludes any bacterial exposure to besifloxacin resulting from systemic use, which further reduces the likelihood of emergence of bacterial resistance. In vitro, besifloxacin has demonstrated equivalent or superior activity compared with other commonly used topical antibiotics. In clinical trials, besifloxacin has consistently demonstrated efficacy and safety in the treatment of patients with bacterial conjunctivitis. Besifloxacin is considered safe and is well tolerated with no observed contraindications.

Keywords: conjunctivitis, fluoroquinolones, besifloxacin, besivance, bacterial conjunctivitis

\section{Introduction}

Conjunctivitis, commonly known as red eye or pink eye, is frequently the result of a bacterial infection but can also be caused by viruses or fungi or result from noninfectious origins, such as allergens, toxins, or the extended use of contact lenses. ${ }^{1-3}$ Bacterial conjunctivitis is a contagious infection of the conjunctiva, the mucous membrane that lines the inner surface of the eyelids and extends over the sclera. ${ }^{1,4}$ Empiric broad-spectrum topical antibacterials are the usual course of therapy for bacterial conjunctivitis. Timely treatment of ocular infections is important, but, clinically, early recognition and treatment of bacterial conjunctivitis is especially significant because of its ability to progress rapidly and potentially cause irreversible ocular damage, including, in rare cases, loss of vision. ${ }^{2,5}$ For example, development of bacterial conjunctivitis after glaucoma-filtering surgery has been reported to increase the patient's risk of developing endophthalmitis. ${ }^{1}$ Broad-spectrum empiric antibiotic therapy for bacterial conjunctivitis has been associated with substantially improved rates of clinical and microbiological remission. ${ }^{6}$

Although empiric antibiotic therapy is administered to prevent spread, speed recovery, alleviate patient discomfort, and avoid potentially serious complications 
such as keratitis, this treatment approach is not without its own potential concerns. As the use of a particular antibiotic increases, the pathogens targeted by that agent tend to evolve and develop resistance, decreasing the treatment's effectiveness over time. ${ }^{7}$ The growing concern regarding antibiotic resistance related to the overuse of empiric antibiotic therapy has led to the search for newer therapies designed to address the development of resistance through innovative or morefocused targeting approaches that restrict nonocular exposure to the antibiotic by limiting systemic availability. This paper will review besifloxacin, a potent new fluoroquinolone antibacterial that has proven efficacy against the most common pathogens of bacterial conjunctivitis, has a uniquely balanced dual-targeting mechanism of action associated with decreased spontaneous resistance development, and was developed exclusively for topical ocular use.

\section{Bacterial conjunctivitis}

Bacterial conjunctivitis results from infections caused by a variety of aerobic and anaerobic bacteria. Aerobic bacteria tend to predominate and most commonly include Haemophilus influenzae, Streptococcus pneumoniae, other streptococci, Staphylococcus aureus, Staphylococcus epidermidis, and Moraxella species. Other, less common bacteria include Neisseria gonorrhoeae, Neisseria meningitides, Pseudomonas species, Proteus species, and Corynebacterium species. ${ }^{2}$

Acute bacterial conjunctivitis is demographically unbiased in its prevalence. It affects individuals of both genders, all ages, and all races. Acute or mucopurulent bacterial conjunctivitis is characterized by mucopurulent or purulent discharge, irritation, and diffuse conjunctival hyperemia. Preauricular lymphadenopathy is usually not present in acute bacterial conjunctivitis. The acute form of the infection is caused by a variety of microbial pathogens; however, infections caused by Haemophilus species, S. pneumoniae, S. aureus, or S. epidermidis tend to be more common. ${ }^{1}$ Bacterial conjunctivitis tends to be transmitted by eye-hand contact and therefore initially presents as a unilateral infection. However, over the course of a few days, the second eye may become infected. ${ }^{8}$ Because of its high incidence rate and broad, nonselective demographics, the treatment of acute bacterial conjunctivitis has been a focus in the development of pharmaceutical therapy.

\section{Traditional treatment options}

Ideally, acute bacterial conjunctivitis should be treated with an antimicrobial agent that targets the causative pathogen, especially in the hospital setting. However, in clinical practice, outpatient treatment of conjunctivitis is often empiric because it is initiated before causative pathogens are identified. ${ }^{3}$ In these cases, treatment is based on the patient's age, environment, and any related ocular observations. Broadspectrum topical antibiotics, usually eyedrops, effectively treat common cases of acute bacterial conjunctivitis and may be given as preventative treatment of a secondary infection in cases of viral conjunctivitis. The antibacterial agent should have activity against $H$. influenzae, $S$. pneumoniae, $S$. aureus, and $S$. epidermidis. ${ }^{9}$ Although acute bacterial conjunctivitis may be self-limiting, effective treatment, such as antibacterial drops, can hasten clinical and microbiological recovery, prevent spread and transmission of the infection, reduce the chance of recurrence, and prevent the rare but potentially serious complications associated with bacterial conjunctivitis. Additional preventative measures for acute bacterial conjunctivitis center around good hygienic practices, including frequent hand washing, avoiding direct contact with the eyes, appropriate handling and cleaning of contact lenses, and regular replacement of eye cosmetics. It is also recommended that pillowcases be changed frequently and towels and handkerchiefs not be shared. ${ }^{1,3}$

\section{Fluoroquinolones}

Fluoroquinolones, a class of broad-spectrum synthetic antiinfective agents, were introduced in the late 1980s and are the most commonly used anti-infectives for the treatment of acute bacterial conjunctivitis. ${ }^{9}$ In the United States, 6 fluoroquinolones are now marketed for ophthalmic use in the treatment of acute bacterial conjunctivitis. They include ciprofloxacin, ofloxacin, levofloxacin, gatifloxacin, moxifloxacin, and besifloxacin. Besifloxacin is the newest fluoroquinolone approved for topical ophthalmic treatment; however, it has unique chemical, structural, and biological features that differentiate it from others in its class. ${ }^{4}$

Fluoroquinolones act, with varying selectivities, through inhibition of the essential bacterial enzymes DNA gyrase and topoisomerase IV. ${ }^{11}$ In other words, they inhibit bacterial type II topoisomerases, leading to nonrepairable double-stranded DNA breaks and death of bacterial cells. DNA gyrase, a topoisomerase found in all types of bacteria, is the primary target for gatifloxacin and moxifloxacin in most Gram-negative bacteria such as Escherichia coli, and, to a much lesser extent, in the Gram-positive species $S$. pneumoniae. On the other hand, topoisomerase IV is usually the primary target for most fluoroquinolones in the majority of Gram-positive pathogens, particularly against prevalent conjunctivitis pathogens such as $S$. aureus and $S$. epidermidis. ${ }^{7,12}$ 
Topical fluoroquinolones approved for ocular use are all considered safe. However, the question of efficacy is ever changing based on the patterns of developing resistance. Newer anti-infective agents with enhanced activity and novel targeting mechanisms may be less prone to resistance and may help address this situation.

\section{Dealing with resistance}

Rates of antibiotic resistance continue to rise in both nosocomial and community settings. ${ }^{7}$ Susceptibility of $S$. pneumoniae and $S$. aureus, two of the most common pathogens found in acute bacterial conjunctivitis, to many commonly employed antibacterial medications have demonstrated dramatic declines over the past decade. A recent study on $S$. aureus that summarized data submitted by more than 200 clinical laboratories across the United States showed that the proportion of methicillin-resistance $S$. aureus (MRSA) isolates from ocular infections increased by $12.1 \%$, from $29.5 \%$ to $41.6 \%$ between 2000 and 2005. ${ }^{13}$ A significant percentage ( 80\%) of ocular MRSA isolates demonstrated in vitro resistance to ciprofloxacin, gatifloxacin, levofloxacin, moxifloxacin, and the aminoglycoside tobramycin. ${ }^{7}$ Patterns of fluoroquinolone resistance for patients with bacterial keratitis have also shown significant increases in resistance of $S$. aureus to ciprofloxacin (from $5.8 \%$ to $35.0 \% ; P<0.001$ ) and ofloxacin (from $4.7 \%$ to $35.0 \% ; P<0.001$ ) between 1993 and $1997 . .^{14}$

The Ocular Tracking Resistance in the United States Today (Ocular TRUST) study evaluated susceptibility patterns to ciprofloxacin, gatifloxacin, levofloxacin, moxifloxacin, azithromycin, tobramycin, and trimethoprim in prospectively collected and archived ocular isolates of

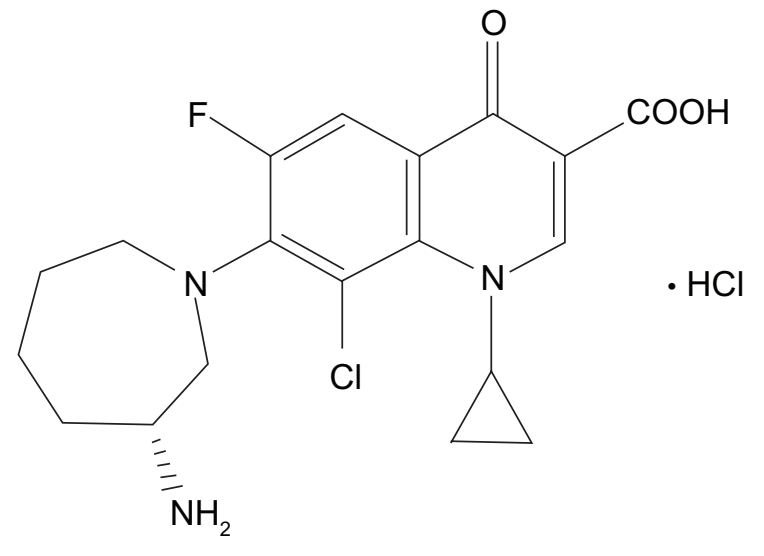

$\mathrm{C}_{19} \mathrm{H}_{21} \mathrm{ClFN}_{3} \mathrm{O}_{3} \cdot \mathrm{HCl}$

Molecular Weight 430.30

Figure I Structure of besifloxacin hydrochloride.
S. aureus, S. pneumoniae, and $H$. influenzae. ${ }^{7}$ Ocular isolates of $S$. pneumoniae demonstrated susceptibility to all the fluoroquinolones tested, with the exception of $10.2 \%$ showing intermediate resistance to ciprofloxacin, one of the oldest fluoroquinolones. However, $22.4 \%$ of the isolates were resistant to trimethoprim, and $65.3 \%$ to tobramycin. Susceptibility of methicillin-susceptible $S$. aureus (MSSA) isolates was high among all the fluoroquinolones tested - ciprofloxacin (79.9\%), levofloxacin (81.1\%), gatifloxacin (81.1\%), and moxifloxacin $(81.1 \%)$ - and the aminoglycoside tobramycin $(92.7 \%)$. However, susceptibility of MSSA to azithromycin was low (54.3\%). Susceptibility of MRSA was low among all the antibacterial agents tested (15.2\% for ciprofloxacin, levofloxacin, gatifloxacin, and moxifloxacin; $6.1 \%$ for azithromycin; and $36.4 \%$ for tobramycin) except trimethoprim (93.9\%). As a result, it has been suggested that the use of older, or earlier-generation, topical fluoroquinolones as first-line empiric therapy in ocular infections is supported, given that the causative pathogen has generally not been MRSA, although the above data indicate that this may be changing. Because treatment of bacterial conjunctivitis is usually empiric, the question then remains, which broad-spectrum topical antibacterial agent would be the most sensible choice for empiric outpatient therapy?

\section{Enhanced technologies and improved therapeutics - besifloxacin}

The continuous hurdle of emerging resistance, including resistance toward older fluoroquinolones, has resulted in a recent focus on newer fluoroquinolones that exhibit enhanced activity against Gram-positive bacteria, namely S. pneumoniae and staphylococci. ${ }^{12}$ This has led most recently to the development of a new fluoroquinolone that may help address the problem with a dual-targeted mechanism of action that is relatively well balanced and has shown reduced development of spontaneous resistance in vitro. Besifloxacin [(+)-7-[(3R)-3-aminohexahydro-1H-azepin-1-yl]-8-chloro-1cyclopropyl-6-fluoro-4-oxo-1,4-dihydroquinolone3-carboxylic acid hydrochloride] is a synthetic fluoroquinolone (Figure 1) indicated for topical use in patients aged 1 year or older for the treatment of bacterial conjunctivitis caused by susceptible isolates of CDC coryneform group G, Corynebacterium pseudodiphtheriticum*, Corynebacterium striatum*, H. influenzae, Moraxella lacunata*, S. aureus, S. epidermidis, Staphylococcus hominis*, Staphylococcus lugdunensis*, Streptococcus mitis group, Streptococcus

*Efficacy for these organisms was studied in fewer than 10 infections. 
oralis, S. pneumoniae, or Streptococcus salivarius. ${ }^{* 15}$ Unlike other fluoroquinolones, besifloxacin is not marketed in other formulations for systemic use. ${ }^{4}$ This ensures that exposure of besifloxacin is limited to the bacterial populations in and around the eye. The exclusive topical ophthalmic use of besifloxacin precludes any bacterial exposure resulting from systemic use, which reduces the likelihood of resistance development. Besifloxacin ophthalmic suspension $0.6 \%$ is formulated in a mucoadhesive polymer (DuraSite ${ }^{\circledR}$; InSite Vision, Inc., Alameda, CA), designed to prolong the drug's residence time on the ocular surface. ${ }^{16}$ The suspension includes $0.01 \%$ benzalkonium chloride as a preservative. Benzalkonium chloride has been shown in vitro to have some bacteriostatic and bactericidal activities. ${ }^{17,18}$

\section{Pharmacokinetics/pharmacodynamics}

In animal studies, besifloxacin demonstrated good ocular penetration, with rapid absorption. A half-life of 5 to 14 hours was seen following a single topical dose, with an average $\mathrm{C}_{\max }$ of $6.43 \mu \mathrm{g} / \mathrm{g}$ in conjunctiva, $2.10 \mu \mathrm{g} / \mathrm{g}$ in cornea, and $0.796 \mu \mathrm{g} / \mathrm{g}$ in aqueous humor of monkeys. ${ }^{19}$ In rabbits, besifloxacin demonstrated a mean residence time of more than 7 hours for tears, conjunctiva, and aqueous humor. ${ }^{20}$ Conjunctival concentrations were in excess of the minimum inhibitory concentration required to inhibit the growth of $90 \%$ of organisms $\left(\mathrm{MIC}_{90}\right)$ for at least 12 hours after a single dose for most Gram-negative and Gram-positive organisms and for nonresistant ophthalmic isolates. Plasma exposure following a single dose was long lived at very low concentrations ( $<10 \mathrm{ng}$ / $\mathrm{mL}$ ), demonstrating minimum systemic exposure. ${ }^{20}$

Plasma protein binding of besifloxacin was low and unvaried across a wide concentration range (10$10,000 \mathrm{ng} / \mathrm{mL}$ ) in rat and human plasma. ${ }^{20}$ In humans, the peak concentration $\left(\mathrm{C}_{\max }\right)$ of besifloxacin in tears following a single topical ocular dose was $610 \mu \mathrm{g} / \mathrm{g}( \pm 540 \mu \mathrm{g} / \mathrm{g})$, decreasing to $1.6 \mu \mathrm{g} / \mathrm{g}$ at 24 hours. ${ }^{19} \mathrm{The}_{\mathrm{max}} / \mathrm{MIC}_{90}$ ratios for besifloxacin in human tears following once-daily, twice-daily, and 3-times-daily dosing regimens were 1220 or greater, and the area under the concentration versus time curve from time 0 to 24 hours $\left(\mathrm{AUC}_{0-24}\right) / \mathrm{MIC}_{90}$ ratios were 2500 or greater against S. pneumoniae $\left(0.125 \mu \mathrm{g} / \mathrm{mL} \mathrm{MIC}_{90}\right)$, S aureus $(0.25 \mu \mathrm{g} / \mathrm{mL}$ $\left.\mathrm{MIC}_{90}\right)$, S. epidermidis $\left(0.5 \mu \mathrm{g} / \mathrm{mL} \mathrm{MIC}_{90}\right)$, and $H$. influenzae $\left(0.06 \mu \mathrm{g} / \mathrm{mL} \mathrm{MIC}_{90}\right)$. In patients with clinically diagnosed bacterial conjunctivitis, the $\mathrm{C}_{\max }$ of besifloxacin in plasma was less than $0.5 \mathrm{ng} / \mathrm{mL}$ on average, following 5 days of repeated 3-times-daily ocular administration. Besifloxacin was eliminated from human tears with an estimated half-life of 3.4 hours. ${ }^{19}$

\section{Mechanism of action}

Whereas older fluoroquinolones have a preference for either DNA gyrase or topoisomerase IV, besifloxacin has a more balanced targeting of both type II topoisomerases (Figure 2). ${ }^{12}$ The structure of besifloxacin contains the $\mathrm{N}$-cyclopropyl group, which is associated with broad-spectrum activity of other fluoroquinolones, such as gatifloxacin and moxifloxacin. In laboratory studies investigating the target selectivity for besifloxacin against $S$. pneumoniae, S. aureus, and $E$. coli, the last as a reference pathogen, DNA gyrase and topoisomerase IV were both shown to be targeted by besifloxacin at nearly equal concentrations. Specifically, besifloxacin had similar activity against $S$. pneumoniae gyrase and topoisomerase IV. Besifloxacin was equally potent against $S$. pneumoniae and E. coli gyrases, which was not the case for ciprofloxacin or moxifloxacin. Based on the inhibitory activity of the antibacterial agents tested, besifloxacin was 5 -fold more potent than was ciprofloxacin and 2-fold more potent than was moxifloxacin against S. pneumoniae topoisomerase IV. The MICs determined for $S$. aureus mutants with defined topoisomerase mutations were also consistently lower for besifloxacin than for either ciprofloxacin or moxifloxacin. In contrast to the older fluoroquinolone comparators, there were no resistant mutants recovered for either $S$. aureus or $S$. pneumoniae at 4-fold $\mathrm{MIC}_{90}$ s for besifloxacin. ${ }^{12}$

The molecular structure of besifloxacin also contains an 8-chloro and a 7-azepinyl substituent, which apparently further enhance potency against both type II topoisomerases found in bacteria. ${ }^{12,20,21}$ This dual targeting theoretically makes besifloxacin less prone to spontaneous resistance development. This is because the simultaneous occurrence of fluoroquinolone-resistant mutations in both DNA gyrase and topoisomerase IV is a highly improbable event, although single-step mutations in genes encoding either of the 2 type II topoisomerases have been frequently reported. ${ }^{22}$ Addition of the 8-chloro and 7-azepinyl substituents present in the molecular structure of besifloxacin has also been associated with enhanced potency and more balanced targeting of both essential type II bacterial topoisomerases, particularly in Gram-positive bacteria. ${ }^{10}$ This results in the potent activity of besifloxacin against Gram-positive bacteria (Table 1), ${ }^{21,23-25}$ Gram-negative bacteria (Table 2), ${ }^{21,25}$ and anaerobic bacteria (Table 3). ${ }^{21}$

\section{Spectrum of activity}

Besifloxacin has demonstrated potent broad-spectrum in vitro activity against aerobic and anaerobic, Gram-positive 


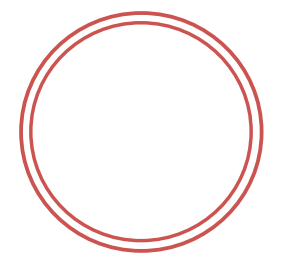

Relaxed DNA

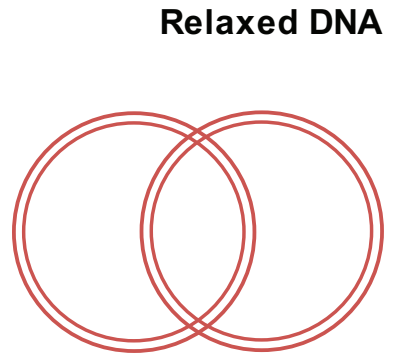

Catenated DNA

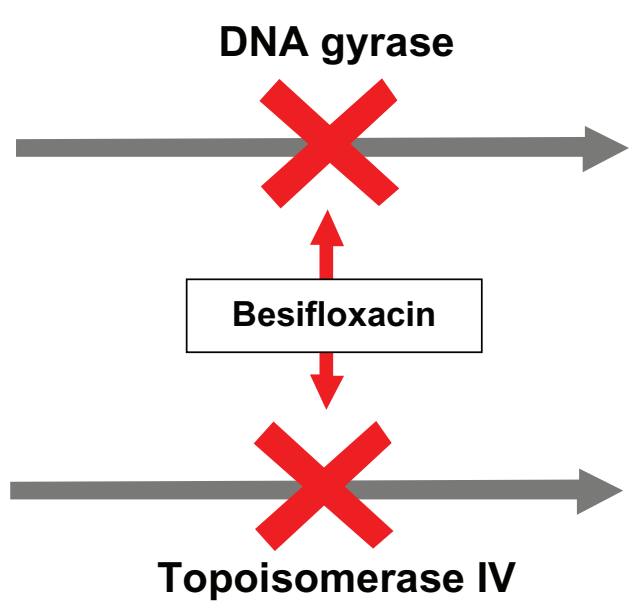

Topoisomerase IV

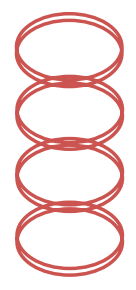

Supercoiled DNA

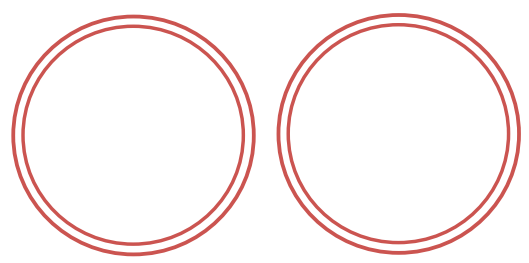

Decatenated DNA

Figure 2 Dual-targeted mechanism of action for besifloxacin.

Besifloxacin binds to and inhibits 2 enzymes that are essential for maintaining bacterial DNA in the proper conformation required for DNA transcription into RNA, DNA replication, and bacterial cell division.

Table I Activities of besifloxacin and other antibiotics against Gram-positive bacteria ${ }^{21}$

\begin{tabular}{|c|c|c|c|}
\hline \multirow[t]{2}{*}{ Species (no. of test isolates) and test drug } & \multicolumn{3}{|c|}{$M I C^{a}(\mu g / m L)$} \\
\hline & Range & $50 \%$ & $90 \%$ \\
\hline \multicolumn{4}{|l|}{ Staphylococcus aureus $\left(n=19 ;\right.$ CIP-S $^{b} ; 21.1 \% M_{R S A}$ ) } \\
\hline Besifloxacin & $0.015-0.25$ & 0.015 & 0.12 \\
\hline Moxifloxacin & $0.015-0.06$ & 0.03 & 0.06 \\
\hline Gatifloxacin & $0.03-1$ & 0.06 & 0.25 \\
\hline Ciprofloxacin & $0.12-0.5$ & 0.25 & 0.5 \\
\hline Levofloxacin & $0.06-2$ & 0.12 & 0.25 \\
\hline Azithromycin & 0.5 to $>8$ & 1 & $>8$ \\
\hline Tobramycin & $0.12-8$ & 0.5 & I \\
\hline Oxacillin & 0.12 to $>8$ & 0.25 & $>8$ \\
\hline \multicolumn{4}{|l|}{ S. aureus $(n=11 ;$ CIP-NS $; 63.6 \%$ MRSA) } \\
\hline Besifloxacin & $0.03-4$ & 0.5 & 4 \\
\hline Moxifloxacin & 0.06 to $>8$ & 4 & $>8$ \\
\hline Gatifloxacin & 0.12 to $>8$ & 4 & $>8$ \\
\hline Ciprofloxacin & 2 to $>8$ & $>8$ & $>8$ \\
\hline Levofloxacin & 0.25 to $>8$ & $>8$ & $>8$ \\
\hline Azithromycin & 0.5 to $>8$ & $>8$ & $>8$ \\
\hline Tobramycin & 0.25 to $>32$ & 1 & $>32$ \\
\hline Oxacillin & 0.12 to $>8$ & $>8$ & $>8$ \\
\hline \multicolumn{4}{|l|}{ Staphylococcus epidermidis ( $\mathrm{n}=9$; CIP-S; 44.4\% MRSE ${ }^{\mathrm{e}}$ ) } \\
\hline Besifloxacin & $0.015-0.03$ & 0.03 & $N A^{f}$ \\
\hline Moxifloxacin & $0.03-0.06$ & 0.06 & NA \\
\hline Gatifloxacin & $0.06-0.06$ & 0.06 & NA \\
\hline Ciprofloxacin & $0.12-0.12$ & 0.12 & NA \\
\hline Levofloxacin & $0.12-0.12$ & 0.12 & NA \\
\hline Azithromycin & 0.25 to $>8$ & $>8$ & NA \\
\hline Tobramycin & $\leq 0.008-8$ & 0.03 & NA \\
\hline Oxacillin & $\leq 0.06-2$ & 0.12 & NA \\
\hline \multicolumn{4}{|l|}{ S. epidermidis ( $n=6$; CIP-NS; 83.3\% MRSE) } \\
\hline Besifloxacin & $0.25-4$ & 0.25 & NA \\
\hline Moxifloxacin & I to $>8$ & 2 & NA \\
\hline
\end{tabular}


Table I (Continued)

\begin{tabular}{|c|c|c|c|}
\hline \multirow[t]{2}{*}{ Species (no. of test isolates) and test drug } & \multicolumn{3}{|l|}{$M^{\prime} C^{a}(\mu g / m L)$} \\
\hline & Range & $50 \%$ & $90 \%$ \\
\hline Gatifloxacin & I to $>8$ & I & NA \\
\hline Ciprofloxacin & 2 to $>8$ & $>8$ & NA \\
\hline Levofloxacin & 2 to $>8$ & 8 & NA \\
\hline Azithromycin & 0.12 to $>8$ & $>8$ & NA \\
\hline Tobramycin & $0.06-16$ & 2 & NA \\
\hline Oxacillin & $0.12-4$ & I & NA \\
\hline \multicolumn{4}{|l|}{ Staphylococcus haemolyticus $(\mathrm{n}=\mathrm{I0I})$} \\
\hline Besifloxacin & $0.015-4$ & 0.5 & I \\
\hline Moxifloxacin & 0.015 to $>8$ & 1 & 8 \\
\hline Gatifloxacin & 0.03 to $>8$ & 2 & 8 \\
\hline Ciprofloxacin & 0.06 to $>8$ & $>8$ & $>8$ \\
\hline Levofloxacin & 0.06 to $>8$ & 4 & $>8$ \\
\hline Azithromycin & 0.25 to $>8$ & $>8$ & $>8$ \\
\hline Tobramycin & 0.015 to $>32$ & 2 & 32 \\
\hline Oxacillin & $\leq 0.06$ to $>8$ & $>8$ & $>8$ \\
\hline \multicolumn{4}{|l|}{ Streptococcus agalactiae $(\mathrm{n}=100)$} \\
\hline Besifloxacin & $0.03-0.12$ & 0.06 & 0.06 \\
\hline Moxifloxacin & $0.06-1$ & 0.12 & 0.25 \\
\hline Gatifloxacin & $0.12-1$ & 0.25 & 0.25 \\
\hline Ciprofloxacin & $0.5-8$ & 0.5 & I \\
\hline Levofloxacin & $0.25-4$ & 0.5 & I \\
\hline Azithromycin & 0.015 to $>8$ & 0.06 & $>8$ \\
\hline Tobramycin & 8 to $>128$ & 32 & 64 \\
\hline Penicillin & $\leq 0.015-0.06$ & 0.03 & 0.06 \\
\hline \multicolumn{4}{|l|}{ Streptococcus pneumoniae $(\mathrm{n}=16$; LVX-Sg) } \\
\hline Besifloxacin & $0.015-0.25$ & 0.03 & 0.06 \\
\hline Moxifloxacin & $0.03-1$ & 0.06 & 0.12 \\
\hline Ciprofloxacin & $0.12-8$ & 0.5 & 2 \\
\hline Levofloxacin & $0.25-2$ & 0.5 & 0.5 \\
\hline Azithromycin & $\leq 0.03$ to $>64$ & 0.06 & $>64$ \\
\hline Tobramycin & $4-32$ & 8 & 16 \\
\hline Penicillin & $\leq 0.06-2$ & $\leq 0.06$ & 0.5 \\
\hline \multicolumn{4}{|l|}{ S. pneumoniae $\left(n=85 ;\right.$ LVX-NS $\left.{ }^{h}\right)$} \\
\hline Besifloxacin & $0.008-1$ & 0.5 & 0.5 \\
\hline Moxifloxacin & $0.25-8$ & 2 & 4 \\
\hline Ciprofloxacin & $\mathrm{I}-64$ & 32 & 64 \\
\hline Levofloxacin & $4-32$ & 16 & 16 \\
\hline Azithromycin & $\leq 0.03$ to $>64$ & 4 & $>64$ \\
\hline Tobramycin & $1-32$ & 8 & 16 \\
\hline Penicillin & $\leq 0.06-2$ & 0.12 & 2 \\
\hline \multicolumn{4}{|l|}{ Streptococcus pyogenes $(\mathrm{n}=\mathrm{I0I})$} \\
\hline Besifloxacin & $0.03-0.06$ & 0.03 & 0.06 \\
\hline Moxifloxacin & $0.06-0.5$ & 0.12 & 0.25 \\
\hline Gatifloxacin & $0.06-0.5$ & 0.12 & 0.25 \\
\hline Ciprofloxacin & $0.12-2$ & 0.5 & 0.5 \\
\hline Levofloxacin & $0.25-2$ & 0.5 & 0.5 \\
\hline Azithromycin & 0.03 to $>8$ & 0.06 & 8 \\
\hline Tobramycin & $4-64$ & 16 & 16 \\
\hline Penicillin & $\leq 0.015-0.06$ & $\leq 0.015$ & $\leq 0.015$ \\
\hline
\end{tabular}

aMinimum inhibitory concentration; ${ }^{b}$ Ciprofloxacin susceptible; ${ }^{C}$ Methicillin-resistant Staphylococcus aureus; ${ }^{\circledR}$ Ciprofloxacin nonsusceptible; ${ }^{~ M e t h i c i l l i n-r e s i s t a n t ~ S t a p h y l o c o c c u s ~}$ epidermidis; ${ }^{N}$ Not available; \& Levofloxacin susceptible; 'Levofloxacin nonsusceptible. 
Table 2 Activities of besifloxacin and other antibiotics against Gram-negative bacteria ${ }^{21}$

\begin{tabular}{|c|c|c|c|}
\hline \multirow[t]{2}{*}{ Species (no. of test isolates) and test drug } & \multicolumn{3}{|l|}{$\operatorname{MIC}^{\mathrm{a}}(\mu \mathrm{g} / \mathrm{mL})$} \\
\hline & Range & $50 \%$ & $90 \%$ \\
\hline \multicolumn{4}{|l|}{ Haemophilus influenzae $(\mathrm{n}=15 ;$ CIP-S $)$} \\
\hline Besifloxacin & $0.008-0.25$ & 0.015 & 0.03 \\
\hline Moxifloxacin & $0.015-0.05$ & 0.015 & 0.06 \\
\hline Ciprofloxacin & $0.008-1$ & 0.008 & 0.015 \\
\hline Levofloxacin & $0.008-1$ & 0.015 & 0.015 \\
\hline Azithromycin & $0.12-2$ & 2 & 2 \\
\hline Tobramycin & $1-16$ & 2 & 8 \\
\hline Penicillin & 0.25 to $>4$ & 0.5 & $>4$ \\
\hline \multicolumn{4}{|l|}{ H. influenzae ( $\mathrm{n}=\mathrm{II}$; CIP-NSc) } \\
\hline Besifloxacin & $0.015-2$ & 2 & 2 \\
\hline Moxifloxacin & $1-16$ & 8 & 16 \\
\hline Ciprofloxacin & $2-64$ & 16 & 64 \\
\hline Levofloxacin & $1-32$ & 8 & 16 \\
\hline Azithromycin & $0.5-8$ & 1 & 8 \\
\hline Tobramycin & $1-16$ & 4 & 8 \\
\hline Penicillin & 0.5 to $>4$ & 1 & 2 \\
\hline \multicolumn{4}{|l|}{ Moraxella catarrhalis $(\mathrm{n}=\mathrm{I0I})$} \\
\hline Besifloxacin & $0.015-0.12$ & 0.03 & 0.03 \\
\hline Moxifloxacin & $0.015-0.12$ & 0.03 & 0.03 \\
\hline Gatifloxacin & $0.008-0.25$ & 0.015 & 0.015 \\
\hline Ciprofloxacin & $0.008-0.25$ & 0.015 & 0.015 \\
\hline Levofloxacin & $0.015-0.5$ & 0.015 & 0.03 \\
\hline Azithromycin & $0.015-0.06$ & 0.03 & 0.03 \\
\hline Tobramycin & $0.03-0.5$ & 0.25 & 0.25 \\
\hline Penicillin & 0.25 to $>8$ & 4 & 8 \\
\hline \multicolumn{4}{|l|}{ Neisseria meningitides $(\mathrm{n}=20)$} \\
\hline Besifloxacin & $\leq 0.004-0.03$ & 0.008 & 0.015 \\
\hline Moxifloxacin & $\leq 0.004-0.015$ & 0.008 & 0.008 \\
\hline Ciprofloxacin & $\leq 0.002-0.015$ & 0.004 & 0.004 \\
\hline Levofloxacin & $\leq 0.004-0.03$ & 0.008 & 0.015 \\
\hline Azithromycin & $\leq 0.03-0.12$ & 0.06 & 0.06 \\
\hline Penicillin & $\leq 0.06-0.25$ & $\leq 0.06$ & 0.12 \\
\hline \multicolumn{4}{|l|}{ Proteus mirabilis $(\mathrm{n}=50)$} \\
\hline Besifloxacin & $0.06-32$ & 0.25 & 16 \\
\hline Moxifloxacin & $0.06-128$ & 0.25 & 16 \\
\hline Ciprofloxacin & 0.015 to $>128$ & 0.03 & 32 \\
\hline Levofloxacin & $0.015-32$ & 0.03 & 8 \\
\hline Imipenem & $0.06-4$ & 1 & 2 \\
\hline Tobramycin & $0.25-32$ & 1 & 4 \\
\hline Ceftazidime & $\leq 0.03-16$ & $\leq 0.03$ & 0.06 \\
\hline \multicolumn{4}{|l|}{ Proteus vulgaris $(\mathrm{n}=50)$} \\
\hline Besifloxacin & $0.06-1$ & 0.12 & 0.25 \\
\hline Moxifloxacin & $0.06-2$ & 0.25 & 0.5 \\
\hline Ciprofloxacin & $0.008-0.12$ & 0.015 & 0.03 \\
\hline Levofloxacin & $0.015-0.25$ & 0.03 & 0.06 \\
\hline Imipenem & $0.25-4$ & 1 & 4 \\
\hline Tobramycin & $0.25-64$ & 1 & 2 \\
\hline Ceftazidime & $\leq 0.03-2$ & 0.06 & 0.12 \\
\hline \multicolumn{4}{|l|}{ Pseudomonas aeruginosa $(\mathrm{n}=105 ;$ CIP-S) } \\
\hline Besifloxacin & $0.5-8$ & 1 & 4 \\
\hline Moxifloxacin & $0.5-16$ & 2 & 4 \\
\hline Ciprofloxacin & $0.03-1$ & 0.12 & 0.5 \\
\hline Levofloxacin & $0.06-4$ & 0.5 & I \\
\hline
\end{tabular}


Table 2 (Continued)

\begin{tabular}{|c|c|c|c|}
\hline \multirow[t]{2}{*}{ Species (no. of test isolates) and test drug } & \multicolumn{3}{|c|}{$M I C^{a}(\mu g / m L)$} \\
\hline & Range & $50 \%$ & $90 \%$ \\
\hline Imipenem & 0.5 to $>8$ & 2 & 2 \\
\hline Tobramycin & 0.25 to $>64$ & 0.5 & 1 \\
\hline Ceftazidime & 0.5 to $>16$ & 2 & 8 \\
\hline \multicolumn{4}{|l|}{ P. aeruginosa $(\mathrm{n}=96 ;$ CIP-NS) } \\
\hline Besifloxacin & $2-128$ & 16 & 64 \\
\hline Moxifloxacin & 2 to $>128$ & 64 & $>128$ \\
\hline Ciprofloxacin & 2 to $>128$ & 16 & 64 \\
\hline Levofloxacin & 2 to $>128$ & 16 & 64 \\
\hline Imipenem & 0.25 to $>8$ & 8 & $>8$ \\
\hline Tobramycin & 0.25 to $>64$ & 1 & $>64$ \\
\hline Ceftazidime & 0.25 to $>16$ & 4 & $>16$ \\
\hline
\end{tabular}

aMinimum inhibitory concentration; ${ }^{\text {}} \mathrm{C}$ iprofloxacin susceptible; ${ }^{\mathrm{c}} \mathrm{C}$ iprofloxacin nonsusceptible.

Table 3 Activities of besifloxacin and other antibiotics against anaerobic bacteria $^{21}$

\begin{tabular}{|c|c|c|c|}
\hline \multirow{2}{*}{$\begin{array}{l}\text { Species (no of test isolates) } \\
\text { and test drug }\end{array}$} & \multicolumn{3}{|l|}{$M I C^{a}(\mu g / m L)$} \\
\hline & Range & $50 \%$ & $90 \%$ \\
\hline \multicolumn{4}{|l|}{ Clostridium perfringens $(\mathrm{n}=2 \mathrm{I})$} \\
\hline Besifloxacin & $0.12-0.25$ & 0.25 & 0.25 \\
\hline Moxifloxacin & $0.25-0.5$ & 0.5 & 0.5 \\
\hline Gatifloxacin & $0.5-1$ & I & I \\
\hline Clindamycin & $0.06-4$ & 2 & 4 \\
\hline Metronidazole & $1-4$ & 2 & 4 \\
\hline \multicolumn{4}{|l|}{ Fusobacterium species $(\mathrm{n}=21)$} \\
\hline Besifloxacin & $0.12-8$ & 0.25 & I \\
\hline Moxifloxacin & 0.25 to $>16$ & 1 & 2 \\
\hline Gatifloxacin & 0.5 to $>16$ & I & 4 \\
\hline Clindamycin & $0.06-8$ & 0.06 & 2 \\
\hline Metronidazole & $\leq 0.12-2$ & 0.25 & I \\
\hline \multicolumn{4}{|l|}{ Peptostreptococcus species $(n=52)$} \\
\hline Besifloxacin & $0.06-2$ & 0.25 & 0.5 \\
\hline Moxifloxacin & $0.25-4$ & 0.25 & 0.5 \\
\hline Ciprofloxacin & 0.5 to $>8$ & 2 & 4 \\
\hline Clindamycin & 0.06 to $>8$ & 0.25 & $>8$ \\
\hline Metronidazole & $\leq 0.03$ to $>16$ & 0.5 & 1 \\
\hline \multicolumn{4}{|l|}{ Propionibacterium acnes $(\mathrm{n}=2 \mathrm{I})$} \\
\hline Besifloxacin & $0.12-0.25$ & 0.25 & 0.25 \\
\hline Moxifloxacin & $0.25-0.25$ & 0.25 & 0.25 \\
\hline Gatifloxacin & $0.25-0.5$ & 0.25 & 0.5 \\
\hline Clindamycin & $\leq 0.03-2$ & 0.06 & 0.12 \\
\hline Metronidazole & $>16$ to $>16$ & $>16$ & $>16$ \\
\hline
\end{tabular}

aMinimum inhibitory concentration. and Gram-negative bacteria, including $H$. influenzae, S. pneumoniae, S. aureus, and S. epidermidis, relative to that of other fluoroquinolones. ${ }^{12,21}$ Besifloxacin, along with nadifloxacin, ofloxacin, and sparfloxacin, was tested in vitro against isolates of Gram-negative, Gram-positive, and anaerobic bacteria. ${ }^{21}$ No substantial differences in MIC values were observed across the 4 fluoroquinolones for the Gram-negative organisms. For Gram-positive bacteria, which included a variety of Staphylococcus species (including MRSA) and Streptococcus species, besifloxacin demonstrated notably more potent inhibition than did ofloxacin. Besifloxacin also demonstrated 4.5-fold more potent inhibition than nadifloxacin and 4.4-fold more potent inhibition than sparfloxacin against Gram-positive bacteria and similar activity to the 2 agents against MRSA. Finally, besifloxacin was significantly more potent against anaerobic bacteria than was either ofloxacin or nadifloxacin. ${ }^{20}$

In a recent laboratory analysis evaluating the broadspectrum activity of besifloxacin, 2690 clinical isolates, including 34 aerobic and 6 anaerobic bacterial species, were tested for susceptibility to besifloxacin and a wide range of other commonly used antibacterial agents, including other fluoroquinolones. ${ }^{21}$ The in vitro activity of besifloxacin against isolates of Gram-negative, Gram-positive, and anaerobic bacteria was generally equivalent or superior to that of topical antibacterial agents commonly used to treat ocular infections. Agents tested included ciprofloxacin, moxifloxacin, levofloxacin, gatifloxacin, azithromycin, and tobramycin, among others. In particular, besifloxacin was 
markedly more potent against non-ciprofloxacin-susceptible $S$. aureus than were all other ophthalmic fluoroquinolones ( $\mathrm{MIC}_{90} 4 \mu \mathrm{g} / \mathrm{mL}$ vs $>8 \mu \mathrm{g} / \mathrm{mL}$, respectively). Besifloxacin was also far more potent than were other fluoroquinolones against staphylococcal isolates that were both methicillinand fluoroquinolone-resistant. In short, the activity of besifloxacin against staphylococci was substantially improved compared with the activities observed for azithromycin, tobramycin, and all other fluoroquinolone comparators. Besifloxacin activity was generally comparable to that of other fluoroquinolones against ciprofloxacin-susceptible isolates of Gram-negative aerobes. Finally, besifloxacin and moxifloxacin were the most active of the agents tested against anaerobic bacteria. Overall, besifloxacin demonstrated potent activity against Gram-positive bacteria that were resistant to other fluoroquinolones. See Tables 1 through 3 for detailed results. ${ }^{21}$

\section{Clinical efficacy}

In clinical trials, besifloxacin has demonstrated efficacy and safety in the treatment of patients with bacterial conjunctivitis. In a phase 3 randomized, multicenter, double-masked, vehicle-controlled trial of 390 patients with culture-confirmed bacterial conjunctivitis, besifloxacin demonstrated significant efficacy in clinical resolution and microbial eradication compared with vehicle. ${ }^{23}$ At day 5, clinical resolution was $45.2 \%$ for besifloxacin, compared with $33.0 \%$ for vehicle $(P=0.0084)$. Microbial eradication was $91.5 \%$ vs $59.7 \%$, respectively $(P<0.0001)$. On day 8 , clinical resolution was $84.4 \%$ vs $69.1 \%$, respectively $(P=0.0011)$, and microbial eradication was $88.4 \%$ vs $71.7 \%$, respectively $(P<0.0001)$.

In another multicenter, prospective, randomized, vehiclecontrolled trial $(\mathrm{N}=118$ culture-confirmed cases of acute bacterial conjunctivitis), patients receiving besifloxacin $(n=60)$ had a significantly higher rate of clinical resolution of baseline symptoms at day 8 than did patients receiving vehicle $(n=58)(73.3 \%$ vs $43.1 \%$, respectively; $P<0.001) .{ }^{24}$ Besifloxacin also had a significantly higher rate of bacterial eradication than did vehicle at this visit $(88.3 \%$ vs $60.3 \%$, respectively; $P<0.001)$. This trial demonstrated that besifloxacin (ophthalmic suspension 0.6\%) 3 times daily for 5 days is effective in attaining clinical resolution of symptoms associated with bacterial conjunctivitis and in eradicating the bacteria that cause the disease.

Finally, in a multicenter, randomized, double-masked, active-controlled noninferiority study of 1161 patients (533 with culture-confirmed bacterial conjunctivitis), besifloxacin was noninferior to moxifloxacin for clinical resolution on day 5 (58.3\% vs $59.4 \%$, respectively; $95 \%$ confidence interval [CI], -9.48 to 7.29$)$ and on day 8 (84.5\% vs $84.0 \%$, respectively; $95 \% \mathrm{CI},-5.67$ to 6.75$).{ }^{25}$ Besifloxacin was also noninferior to moxifloxacin for microbial eradication on day 5 (93.3\% vs $91.1 \%$, respectively; 95\% CI, -2.44 to 6.74$)$ and on day $8(87.3 \%$ vs $84.7 \%$, respectively; $95 \%$ CI, -3.32 to 8.53 ).

\section{Safety and tolerability}

Besifloxacin is considered safe and is well tolerated with no observed contraindications. In clinical trials, the most common adverse event reported was conjunctival redness, occurring in approximately $2 \%$ of patients. ${ }^{15}$ Tables $4^{26}$ and $5^{27}$ highlight the most common treatment-emergent ocular adverse events observed across the above-mentioned 3 clinical studies for study eyes and for all treated eyes (patients with bilateral conjunctivitis had both the study eye and fellow eye treated), respectively.

Data drawn from phase 1 studies demonstrated that topical ocular administration of besifloxacin resulted in negligible systemic exposure, with no changes in corneal endothelial cell density. ${ }^{27}$ In a vehicle-controlled trial of 957 adult patients with bacterial conjunctivitis, a greater percentage of eyes treated with vehicle experienced adverse effects than did those treated with besifloxacin (13.9\% vs $9.2 \%$, respectively; $P=0.0047) .{ }^{23}$ In another randomized, vehicle-controlled trial of 118 patients, there was no significant difference of cumulative adverse events between placebo and besifloxacin groups. ${ }^{24}$ Finally, in a randomized trial of 1161 patients treated with either besifloxacin or moxifloxacin, both drugs were well tolerated. ${ }^{25}$ Patients treated with moxifloxacin

Table 4 Pooled analysis: treatment-emergent ocular adverse events (AEs) in $\geq 1.0 \%$ of all treated study eyes in any treatment group ${ }^{26}$

\begin{tabular}{|c|c|c|c|c|}
\hline & \multicolumn{4}{|c|}{ Patients, n (\%) } \\
\hline & $\begin{array}{l}\text { Besifloxacin } \\
(n=1 / 92)\end{array}$ & $\begin{array}{l}\text { Vehicle } \\
(n=616)\end{array}$ & $\begin{array}{l}\text { Moxifloxacin } \\
(n=579)\end{array}$ & $P$ value $^{a}$ \\
\hline Total no. of AEs & 191 & 146 & 81 & \\
\hline $\begin{array}{l}\text { Patients with } \\
\geq \mathrm{IAE}\end{array}$ & $139(11.7)$ & $\begin{array}{c}101 \\
(16.4)\end{array}$ & $54(9.3)$ & 0.0055 \\
\hline Vision blurred & $25(2.1)$ & $24(3.9)$ & $3(0.5)$ & 0.0318 \\
\hline Eye irritation & $17(1.4)$ & $18(2.9)$ & $8(1.4)$ & 0.0457 \\
\hline Eye pain & $22(1.8)$ & II (I.8) & $7(1.2)$ & $>0.9999$ \\
\hline Conjunctivitis & $14(1.2)$ & I5 (2.4) & $5(0.9)$ & 0.0492 \\
\hline Eye pruritus & $13(1.1)$ & $10(1.6)$ & $2(0.3)$ & 0.3777 \\
\hline $\begin{array}{l}\text { Conjunctivitis, } \\
\text { bacterial }\end{array}$ & $7(0.6)$ & $9(1.5)$ & $2(0.3)$ & 0.0678 \\
\hline
\end{tabular}

${ }^{a} P$ values were based on Fisher's exact test comparing besifloxacin with vehicle. 
Table 5 Pooled analysis: treatment-emergent ocular adverse events (AEs) in $\geq 1 \%$ of all treated eyes ${ }^{\mathrm{a}}$ in any treatment group (safety population $)^{27}$

\begin{tabular}{|c|c|c|c|c|}
\hline & $\begin{array}{l}\text { Besifloxacin } \\
(n=|8| 0) \\
n(\%)\end{array}$ & $\begin{array}{l}\text { Vehicle } \\
(n=96 I) \\
n(\%)\end{array}$ & $\begin{array}{l}\text { Vigamox } \\
(\mathrm{n}=855) \\
\mathrm{n}(\%)\end{array}$ & $P$ value $^{b}$ \\
\hline $\begin{array}{l}\text { Total no of } \\
\text { ocular AEs }\end{array}$ & 327 & 258 & 153 & \\
\hline $\begin{array}{l}\text { Eyes with } \\
\geq I A E\end{array}$ & $249(13.8)$ & $190(19.8)$ & $120(14.0)$ & $<0.0001$ \\
\hline Conjunctivitis & $47(2.6)$ & $4 \mid(4.3)$ & $33(3.9)$ & 0.0223 \\
\hline Vision blurred & $38(2.1)$ & $39(4.1)$ & $4(0.5)$ & 0.0035 \\
\hline $\begin{array}{l}\text { Conjunctivitis, } \\
\text { bacterial }\end{array}$ & $32(1.8)$ & $27(2.8)$ & $22(2.6)$ & 0.0736 \\
\hline Eye irritation & $26(1.4)$ & $27(2.8)$ & $12(1.4)$ & 0.0187 \\
\hline Eye pain & $28(1.5)$ & $17(1.8)$ & $9(1.1)$ & 0.6396 \\
\hline Eye pruritus & $18(1.0)$ & $18(1.9)$ & $3(0.4)$ & 0.0761 \\
\hline
\end{tabular}

${ }^{a}$ Treated eyes, including study and fellow eyes; ${ }^{b} P$ values for besifloxacin compared with vehicle (Fisher's exact test).

did have a significantly higher incidence of eye irritation (1.4\% vs $0.3 \%$ for besifloxacin; $P=0.0201$ ); however, all other adverse events occurred with similar frequency between both agents.

A subanalysis of adverse events among patients less than 6 years of age from the above studies demonstrated the safety and efficacy of besifloxacin ophthalmic suspension $0.6 \%$ in this population. ${ }^{28}$ The most common adverse events reported in patients less than 6 years of age were conjunctivitis $(2.1 \%, 7 / 331)$, bacterial conjunctivitis $(1.8 \%, 6 / 331)$, conjunctival hemorrhage $(1.2 \%, 4 / 331)$, viral conjunctivitis $(1.2 \%, 4 / 331)$, and eye pain $(1.2 \%, 4 / 331)$. As an adverse event, conjunctivitis was reported less frequently in patients receiving besifloxacin than in patients receiving vehicle.

Finally, in a rabbit wound-healing model using dexamethasone as a positive control, planimetry measurements showed that besifloxacin did not impede corneal reepithelialization compared with saline at 72 hours. ${ }^{29}$

\section{Dosing}

The recommended dosage of besifloxacin is 1 drop of the besifloxacin ophthalmic suspension $0.6 \%$ in the affected eye 3 times a day, at intervals of 4 to 12 hours, for a total of 7 days. ${ }^{15}$ The dosing frequency for besifloxacin is similar to that for moxifloxacin, whereas other ophthalmic fluoroquinolones are administered more frequently, ${ }^{4}$ possibly leading to compliance issues, an important consideration in the fight against emerging microbial resistance. Compliance has been shown to be inversely related to frequency and complexity of dosing. ${ }^{30}$ The convenience of besifloxacin is further enhanced by the recommended intervals between doses, which can range from 4 to 12 hours, adding a degree of flexibility. ${ }^{15}$

Besifloxacin is supplied as an ophthalmic suspension with benzalkonium chloride as a preservative, and the closed bottle should be inverted and shaken once prior to use.

\section{Conclusions}

Besifloxacin is a novel synthetic, broad-spectrum fluoroquinolone recently approved for the treatment of bacterial conjunctivitis. Clinical trials have demonstrated superior efficacy of besifloxacin to that of vehicle and clinical equivalence (noninferiority) to that of moxifloxacin. In vitro, besifloxacin has demonstrated potent activity often superior to that of other commonly used topical anti-infectives. Besifloxacin has a uniquely balanced dual-targeting activity that inhibits both DNA gyrase and topoisomerase IV and potentially hinders the rise of resistance. Unlike other fluoroquinolones, besifloxacin has highly selective usage. It is formulated only for ocular use and is neither marketed nor in development in formulations for systemic administration. The reduced exposure of besifloxacin to bacterial populations will presumably limit the likelihood of the emergence of bacterial resistance resulting from any nonocular exposure to the drug, although crossresistance from other fluoroquinolones has been observed. Taking into account the changing susceptibility profiles of the major causative pathogens, the first-line use of a potent new ophthalmic fluoroquinolone with a lower potential for resistance development may result in an improved resistance development profile relative to that of the other ophthalmic fluoroquinolones, all of which have also been used for more than 10 years in a broad variety of nonophthalmic health care - and community-associated infection settings.

\section{Disclosures}

TLC, TWM, JZ disclose being employees of Bausch and Lomb, Inc.

PMK discloses that he is a paid consultant for AMO, Allergan Inc., Bausch and Lomb, Inc., Cyanacon Ocusoft, Eyemaginations, Focus Laboratories, Inspire Pharmaceuticals, Pixel Optics, Odyssey Medical, Office Mate/VSP, Rapid Pathogen Screening, Science Based Health, Sirion Therapeutics, VMax. Advisor for LCA Vision-LASIK Plus, OcuSense/TearLab and share holder for Inspire Pharmaceuticals, OcuSense/TearLab and VMax.

Editorial support was provided by Phocus Inc. 


\section{References}

1. American Optometric Association. Care of the patient with conjunctivitis. Optometric clinical practice guideline. http://www.aoa.org/documents/ CPG-11.pdf. Accessed September 22, 2009.

2. Brook I. Ocular infections due to anaerobic bacteria in children. J Pediatr Ophthalmol Strabismus. 2008;45(2):78-84.

3. Tarabishy AB, Jeng BH. Bacterial conjunctivitis: a review for internists. Cleve Clin J Med. 2008;75(7):507-512.

4. Hussar DA. New drugs: golimumab, besifloxacin hydrochloride, and artemether/lumefantrine. J Am Pharm Assoc (2003). 2009;49(4): 570-574.

5. Cavuoto K, Zutshi D, Karp CL, Miller D, Feuer W. Update on bacterial conjunctivitis in South Florida. Ophthalmology. 2008;115(1):51-56.

6. Sheikh A, Hurwitz B. Antibiotics versus placebo for acute bacterial conjunctivitis. Cochrane Database Syst Rev. 2006;2:CD001211.

7. Asbell PA, Colby KA, Deng S, et al. Ocular TRUST: nationwide antimicrobial susceptibility patterns in ocular isolates. Am J Ophthalmol. 2008;145(6):951-958.

8. Morrow GL, Abbott RL. Conjunctivitis. Am Fam Physician. 1998;57(4):735-746.

9. Diamant JI, Hwang DG. Therapy for bacterial conjunctivitis. Ophthalmol Clin North Am. 1999;12(1):15-20.

10. Arnold DR, Granvil CP, Ward KW, Proksch JW. Quantitative determination of besifloxacin, a novel fluoroquinolone antimicrobial agent, in human tears by liquid chromatography-tandem mass spectrometry. J Chromatogr B Analyt Technol Biomed Life Sci. 2008;867(1): $105-110$

11. Dalhoff A, Shalit I. Immunomodulatory effects of quinolones. Lancet Infect Dis. 2003;3(6):359-371.

12. Cambau E, Matrat S, Pan XS, et al. Target specificity of the new fluoroquinolone besifloxacin in Streptococcus pneumoniae, Staphylococcus aureus and Escherichia coli. J Antimicrob Chemother. 2009;63(3): 443-450.

13. Asbell PA, Sahm DF, Shaw M, Draghi DC, Brown NP. Increasing prevalence of methicillin resistance in serious ocular infections caused by Staphylococcus aureus in the United States: 2000 to 2005. J Cataract Refract Surg. 2008;34(5):814-818.

14. Goldstein MH, Kowalski RP, Gordon YJ. Emerging fluoroquinolone resistance in bacterial keratitis: a 5-year review. Ophthalmology. 1999;106(7):1313-1318.

15. Besivance [package insert]. Tampa, FL: Bausch and Lomb Inc: 2009.

16. Protzko E, Bowman L, Abelson M, et al. Phase 3 safety comparisons for $1.0 \%$ azithromycin in polymeric mucoadhesive eye drops versus $0.3 \%$ tobramycin eye drops for bacterial conjunctivitis. Invest Ophthalmol Vis Sci. 2007;48(8):3425-3429.

17. McDonnell G, Russell AD. Antiseptics and disinfectants: activity, action, and resistance. Clin Microbiol Rev. 1999;12(1):147-179.
18. Blondeau JM, Borsos S, Hesje CK. Antimicrobial efficacy of gatifloxacin and moxifloxacin with and without benzalkonium chloride compared with ciprofloxacin and levofloxacin against methicillin-resistant Staphylococcus aureus. J Chemother. 2007;19(2):146-151.

19. Proksch JW, Granvil CP, Siou-Mermet R, Comstock TL, Paterno MR, Ward KW. Ocular pharmacokinetics of besifloxacin following topical administration to rabbits, monkeys, and humans. J Ocul Pharmacol Ther. 2009;25(4):335-344.

20. Ward KW, Lepage JF, Driot JY. Nonclinical pharmacodynamics, pharmacokinetics, and safety of BOL-303224-A, a novel fluoroquinolone antimicrobial agent for topical ophthalmic use. J Ocul Pharmacol Ther. 2007;23(3):243-256.

21. Haas W, Pillar CM, Zurenko GE, Lee JC, Brunner LS, Morris TW. Besifloxacin, a novel fluoroquinolone, has broad-spectrum in vitro activity against aerobic and anaerobic bacteria. Antimicrob Agents Chemother. 2009;53(8):3552-3560.

22. Hwang DG. Fluoroquinolone resistance in ophthalmology and the potential role for new ophthalmic fluoroquinolones. Surv Ophthalmol. 2004;49(Suppl 2):S79-S78.

23. Tepedino ME, Heller WH, Usner DW, et al. Phase III efficacy and safety study of besifloxacin ophthalmic suspension $0.6 \%$ in the treatment of bacterial conjunctivitis. Curr Med Res Opin. 2009;25(3):1159-1169.

24. Karpecki P, Depaolis M, Hunter JA, et al. Besifloxacin ophthalmic suspension $0.6 \%$ in patients with bacterial conjunctivitis: a multicenter, prospective, randomized, double-masked, vehicle-controlled, 5-day efficacy and safety study. Clin Ther. 2009;31(3):514-526.

25. McDonald MB, Protzko EE, Brunner LS, et al. Efficacy and safety of besifloxacin ophthalmic suspension $0.6 \%$ compared with moxifloxacin ophthalmic solution $0.5 \%$ for treating bacterial conjunctivitis. Ophthalmology. 2009;116(9):1615-1623.e1.

26. Data on file. Bausch and Lomb. Rochester, NY.

27. Paterno MR, Comstock TL, Lynch JA, Usner DW. Besifloxacin ophthalmic suspension $0.6 \%$ is safe and well tolerated in patients with bacterial conjunctivitis. Invest Ophthalmol Vis Sci. 2009;50:E-Abstract 2674.

28. Comstock TL, Paterno MR, Lynch JA, DeCory HH, Usner DW. Efficacy and safety of besifloxacin ophthalmic suspension $0.6 \%$ in pediatric patients with bacterial conjunctivitis. Optometry. 2009;80(6): 296-297.

29. Zhang JZ, Krenzer KL, López FJ, Ward KW. Comparative effects of besifloxacin and other fluoroquinolones on corneal reepitheliazation in the rabbit. Presented at: 5th International Conference on Ocular Infections; February 18-21, 2010; Palm Beach, FL.

30. Claxton AJ, Cramer J, Pierce C. A systematic review of the associations between dose regimens and medication compliance. Clin Ther. 2001;23(8):1296-1310.
Clinical Ophthalmology

\section{Publish your work in this journal}

Clinical Ophthalmology is an international, peer-reviewed journal covering all subspecialties within ophthalmology. Key topics include: Optometry; Visual science; Pharmacology and drug therapy in eye diseases; Basic Sciences; Primary and Secondary eye care; Patient Safety and Quality of Care Improvements. This journal is indexed on Submit your manuscript here: http://www.dovepress.com/clinical-ophthalmology-journal

\section{Dovepress}

PubMed Central and CAS, and is the official journal of The Society of Clinical Ophthalmology (SCO). The manuscript management system is completely online and includes a very quick and fair peer-review system, which is all easy to use. Visit http://www.dovepress.com/ testimonials.php to read real quotes from published authors. 